\title{
Helicobacter pylori VacA cytotoxin associated with the bacteria increases epithelial permeability independently of its vacuolating activity
}

\author{
Vladimir Pelicic, ${ }^{1}$ Jean-Marc Reyrat, ${ }^{2}$ Lucia Sartori, ${ }^{1}$ Cristina Pagliaccia, ${ }^{2}$ \\ Rino Rappuoli, ${ }^{2}$ John L. Telford, ${ }^{2}$ Cesare Montecucco' \\ and Emanuele Papini' ${ }^{1}+$ \\ Author for correspondence: Emanuele Papini. Tel: +39498276077 . Fax: +39498276049. \\ e-mail: papinie@civ.bio.unipd.it
}

1 Dipartimento di Scienze Biomediche, Università di Padova, Viale G. Colombo 3, 35121 Padova, Italy

2 IRIS, Chiron-SpA, Via Fiorentina 1, 53100 Siena, Italy

\begin{abstract}
Polarized epithelial monolayers of Madin-Darby canine kidney (MDCK) cells were used to study the pathogenicity of Helicobacter pylori, with an emphasis on the effect of VacA. The adherence of $H$. pylori to MDCK monolayers resulted in a decrease in trans-epithelial resistance (TER) across the cell monolayer. Isogenic vacA mutants did not lower the TER, demonstrating that the effect is strictly linked to the action of the toxin. A similar effect was observed with all VacA-producing strains, including those producing $\mathbf{m} 2$ toxins that are inactive in the vacuolating assay. In contrast to that seen with purified toxin, TER decrease was not enhanced by acid pH, which may indicate that the toxin associated to the bacterial surface is possibly in a monomeric state and therefore does not require a pH-induced conformation to be active. These data raise the possibility that one role of VacA in ulcerogenesis may consist of increasing the paracellular permeability of the gastric epithelium.
\end{abstract}

Keywords: VacA, Helicobacter pylori, epithelial permeability, gastritis, ulcerogenesis

\section{INTRODUCTION}

Helicobacter pylori has evolved sophisticated virulence determinants that have enabled it to colonize the gastric mucosa of more than $50 \%$ of the world's population, making it probably the most common chronic bacterial infection of humans (Blaser, 1993). This micro-organism establishes lifelong, mostly asymptomatic infections, though invariably accompanied by a mild inflammation of the gastric mucosa termed chronic superficial gastritis. Nevertheless, epidemiological studies have demonstrated that $H$. pylori infections can lead to severe gastric diseases including atrophic gastritis, peptic ulcers and gastric adenocarcinomas (Figura et al., 1989; Parsonnet et al., 1991).

Putative virulence factors that may contribute to different steps of $H$. pylori pathogenicity have been

\footnotetext{
†Present address: Dipartimento di Scienze Biomediche e Oncologia Umana, Università di Bari, Piazza Giulio Cesare 11, 70100 Bari, Italy.

Abbreviations: CA, Columbia agar; DMEM, Dulbecco's modified Eagle medium; MDCK, Madin-Darby canine kidney; NRU, neutral-red uptake; TER, trans-epithelial resistance.
}

identified (Labigne \& de Reuse, 1996). Among these, genes from the cag pathogenicity island and the vacuolating cytotoxin VacA deserve a special mention because they are almost invariably expressed in the highly virulent strains isolated from patients with severe forms of gastric diseases (Xiang et al., 1995). The $40 \mathrm{~kb}$ cag pathogenicity island (Akopyants et al., 1998; Censini et al., 1996), discovered during the genetic characterization of the immunodominant antigen CagA, encodes several genes which are involved in the induction of interleukin 8 secretion by target cells (Akopyants et al., 1998; Segal et al., 1997), a phenomenon thought to be essential for the onset of a strong and persistent inflammatory response. On the other hand, epidemiological (Figura et al., 1989) and experimental evidence (Marchetti et al., 1995; Telford et al., 1994) has clearly demonstrated the association between VacA production and the occurrence of tissue damage. Indeed, using the mouse (Marchetti et al., 1995; Telford et al., 1994) or the beagle dog (Radin et al., 1990) as animal models, it is possible to induce gastric erosion by orally administrating either VacA-producing strains or purified VacA toxin. 
Mature VacA can be processed into two associated subunits of 37 and $58 \mathrm{kDa}$ (Telford et al., 1994) and oligomerizes into rosette-shaped structures with six or seven petals (Cover et al., 1997; Lupetti et al., 1996). The toxin is bound and internalized by target cells following a process that is specific and saturable, suggesting that it is mediated by still-unidentified high-affinity cell-surface receptors (Garner \& Cover, 1996; Massari et al., 1998). Moreover, transfection experiments where vacA has been expressed intracellularly have indicated that the toxin induces vacuole formation from the cytoplasm (de Bernard et al., 1997). These data suggest that VacA may belong to the family of $A B$ di-chain toxins, with a catalytic A domain ( $37 \mathrm{kDa}$ subunit) acting on an as-yet unknown intracellular target after membrane binding and translocation into the cytosol assisted by the B moiety (58 kDa subunit) (Montecucco et al., 1994). The best known VacA effect is its ability to induce cytoplasmic vacuoles in various eukaryotic cell lines (Leunk et al., 1988) by altering intracellular membrane traffic at the late endosomal/prelysosomal level (Molinari et al., 1997; Papini et al., 1994, 1997). The toxin is also responsible for functional defects preceding vacuolar degeneration such as (i) mistargeting of acidic hydrolases (Satin et al., 1997), (ii) impairment of proteolytic degradation inside lysosomes (Satin et al., 1997) and (iii) inhibition of li-dependent antigen processing (Molinari et al., 1998a). In addition to these alterations seen in non-polarized target cells, a new effect has been recently identified in vitro using polarized epithelial cell monolayers. Purified VacA was found to increase the permeability of such monolayers to low-molecular-mass molecules by an uncharacterized molecular mechanism (Papini et al., 1998). Nevertheless, it has been shown that the trans-epithelial resistance (TER) decrease does not result from (i) disruption of the intercellular junctions, (ii) acute cytotoxicity or (iii) intracellular vacuolation. Whether any of the above toxic effects is actually relevant to pathogenesis remains to be determined under more physiological conditions, using whole bacteria. In the absence of gastric cell lines able to differentiate into sealed monolayers in vitro, epithelial cells that can differentiate into tightly sealed monolayers represent a valuable alternative to complex animal models.

In this study, we have tested whether polarized monolayers of Madin-Darby canine kidney (MDCK) cells could be a suitable in vitro model of infection by $H$. pylori and examined any possible role of other bacterial factors, in addition to VacA, on the integrity of such monolayers. We found that MDCK monolayers are indeed suitable for studying $H$. pylori pathogenicity because the bacterium readily binds to their apical surface. Following bacterial adhesion, the TER of the monolayers decreases in a dose-dependent fashion. This effect is due exclusively to VacA expression, as clearly demonstrated by a mutational analysis, and is readily apparent at very low bacterial doses. Moreover, we provide evidence that this effect is due exclusively to the toxin exposed on the bacterial surface. Interestingly, a similar effect was observed with all VacA-producing strains, including those producing $\mathrm{m} 2$ toxins that are commonly considered as inactive because they are inactive in the vacuolating assay. The possible relevance of these phenomena in ulcerogenesis is discussed.

\section{METHODS}

Bacterial strains and culture conditions. H. pylori strains used in this study and their relevant characteristics are listed in Table 1. vacA isogenic $H$. pylori mutants were constructed by allelic exchange. The vector used for mutagenesis (pJMR1) was constructed by inserting the kanamycin-resistance cassette from pBK53K (Trieu-Cuot et al., 1985), present on a Smal fragment, into the blunt-ended EcoNI site present in the $v a c A$ gene cloned into pTOX140 (Manetti et al., 1995). Bacteria were naturally transformed with $1 \mu \mathrm{g}$ pJMR 1 . Several $\mathrm{Km}^{r}$ clones, selected on plates containing $20 \mu \mathrm{g}$ kanamycin $\mathrm{ml}^{-1}$, were analysed by Southern and Western blotting and were shown to be allelic exchange mutants. Bacteria were grown on Columbia agar (CA) plates supplemented in the following order with $5 \mathrm{mg}$ vancomycin $\mathrm{I}^{-1}, 10 \mathrm{mg}$ trimethoprim $\mathrm{l}^{-1}, 6 \mathrm{mg}$ cefsulodin $\mathrm{I}^{-1}, 9 \mathrm{mg}$ amphotericin $\mathrm{B} \mathrm{I}^{-1}, 0.2 \%$ cyclodextrin, $5 \%$ defibrinated horse blood and $100 \mathrm{mg}$ cycloheximide $1^{-1}$ (Marchini et al., 1994). The plates were incubated for $2 \mathrm{~d}$ at $37^{\circ} \mathrm{C}$ under moist atmosphere in an Oxoid anaerobic jar containing a gas-generating kit (Unipath). To avoid any secondary variation, all the infection assays were performed with jar-grown cultures of single frozen bacterial stocks conserved at $-80^{\circ} \mathrm{C}$ in $\mathrm{BHI}$ medium supplemented with $20 \%$ glycerol, $0 \cdot 2 \%$ cyclodextrin and $10 \%$ foetal calf serum.

Formation of cell monolayers and integrity assays. MDCK cells can form polarized monolayers on Transwell polycarbonate membrane filters (Corning Costar). The barrier function of such monolayers, depending on the formation of tight junctions, can be assessed by monitoring the TER with a Millicell-ERS apparatus (Millipore). Monolayers with high TER values, between 11000 and $14000 \Omega$ per $\mathrm{cm}^{2}$, were obtained within 10-14 days as described (Papini et al., 1998).

Infection of monolayers. Before the infection, the medium was removed from both compartments of a Transwell unit and replaced with fresh DMEM (Dulbecco's modified Eagle medium) containing no gentamicin. In order for the TER to stabilize, the filters were incubated for approximately $1 \mathrm{~h}$ at $37{ }^{\circ} \mathrm{C}$ under $5 \% \mathrm{CO}_{2}$. In the meantime, bacteria were harvested from CA plates in DMEM, resuspended by 2 passages through a gauge needle and diluted in the same medium to a final $\mathrm{OD}_{600}$ of 1 (approx. $2.6 \times 10^{8}$ c.f.u. $\mathrm{ml}^{-1}$ ). The medium from the Transwell unit top compartment was removed, $500 \mu \mathrm{l}$ bacterial inocula of defined concentration were added, and the filters were further incubated at $37^{\circ} \mathrm{C}$ under $5 \% \mathrm{CO}_{2}$. The integrity of the monolayers was assessed by measuring the TER every hour.

When indicated, the CCUG isogenic vacA mutant was functionally complemented with purified $\mathrm{VacA}$ toxin as follows. Bacterial suspension $(1 \mathrm{ml})$ at $\mathrm{OD}_{\text {fion }}$ of 1 was mixed with $100 \mathrm{nM}$ purified toxin (Manetti et al., 1995) and incubated for $5 \mathrm{~min}$ at $37^{\circ} \mathrm{C}$. Whether the toxin was pretreated by a short exposure at $\mathrm{pH} 2$ or not, the final $\mathrm{pH}$ of the solution was around neutrality. Bacteria were then pelleted by centrifuging at $1000 \mathrm{~g}$ for $5 \mathrm{~min}$, gently resuspended in $1 \mathrm{ml}$ fresh DMEM and used to infect the monolayers. 
Table 1. H. pylori strains used in this study and their relevant characteristics

\begin{tabular}{|llcc|}
\hline Strain & \multicolumn{1}{c}{ Relevant characteristics } & VacA production* & VacA activity \\
\hline CCUG 17874 & Strain producing s1m1 VacA & + & + \\
CCUG vacA & CCUG 17874 vacA:: Km isogenic & - & - \\
& mutant & + & + \\
SPM 326 & Strain producing s1m1 VacA & - & - \\
SPM 326 vacA & SPM 326 vacA::Km isogenic mutant & + & - \\
$95-54$ & Strain producing s1m2 VacA & - & - \\
$95-54$ vacA & 95-54 vacA::Km isogenic mutant & & \\
\hline
\end{tabular}

"Assessed by immunoblotting.

† Ability of bacterial water extracts to induce vacuolation in HeLa or MDCK cells.

Quantification of adherent bacteria. Viable bacteria adhering to the monolayers were quantified as described by CorthésyTheulaz et al. (1996). In brief, the adhesion was allowed to proceed at $37{ }^{\circ} \mathrm{C}$ under $5 \% \mathrm{CO}_{2}$ for $1,2,4$ or $21 \mathrm{~h}$. The monolayers were then washed eight times with sterile PBS to remove all non-adherent bacteria. The cells with adherent bacteria were recovered by adding a freshly thawed solution of trypsin/EDTA to both compartments of the Transwell unit and incubating for $10 \mathrm{~min}$ at $37{ }^{\circ} \mathrm{C}$ under $5 \% \mathrm{CO}_{2}$. Adherent bacteria were dispersed by vigorous pipetting and enumerated by plating serial dilutions on CA plates that were incubated for $4-5 \mathrm{~d}$ at $37^{\circ} \mathrm{C}$ under a $5 \% \mathrm{CO}_{2}$ atmosphere.

Quantification of cell vacuolation. Bacteria were harvested from CA plates in distilled water and diluted to a final $\mathrm{OD}_{600}$ of 1 . Surface proteins were separated from the bacteria by vortexing at room temperature for $2 \mathrm{~min}$. Supernatants that were recovered after a $5 \mathrm{~min}$ centrifugation at $14000 \mathrm{~g}$ were subsequently filter-sterilized using $0 \cdot 2 \mu \mathrm{m}$ pore-size filters. The extent of vacuolation induced in MDCK cells by serial dilutions of the water extracts was quantified spectrophotometrically by measuring the neutral-red uptake (NRU) as previously described for HeLa cells (Papini et al., 1993), except that cells were seeded on 96 well plates at a density of 8000 cells per well.

Western blotting. Bacteria were resuspended to a final $\mathrm{OD}_{600}$ of 1 in DMEM without foetal calf serum. After a $5 \mathrm{~min}$ centrifuation at $10000 \mathrm{~g}$, pellets were resuspended in $200 \mu \mathrm{l}$ loading buffer. The supernatants, first precipitated with trichloroacetic acid, were resuspended in $200 \mu$ loading buffer as well. Western blotting was then performed using an antiVacA serum as previously described (de Bernard et al., 1997) and the ECL analysis system (Amersham) for detection.

Measurement of $\left[{ }^{14} \mathrm{C}\right]$ mannitol paracellular flux. Changes in paracellular permeability of the monolayers in response to bacterial infection were assayed by measuring the penetration of $\left[{ }^{14} \mathrm{C}\right]$ mannitol, a marker molecule of small size $\left(\mathrm{M}_{\mathrm{r}} 182 \cdot 2\right)$. In brief, after overnight bacterial infection, $4 \times 10^{6}$ c.p.m. $\left[{ }^{14} \mathrm{C}\right]$ mannitol was added to the Transwell lower compartment and the monolayers were incubated at $37^{\circ} \mathrm{C}$. At defined time periods, the medium in the apical compartment was removed, replaced with fresh medium and counted by liquid scintillation counting.

Statistics. Each experiment was done at least in triplicate. Results are reported as means \pm standard deviation. Bars, representing the standard deviations, are generally too small to be visible on the graphs.

\section{RESULTS}

\section{H. pylori adheres to MDCK monolayers}

H. pylori binds in vitro to numerous cell lines of various origins (Labigne \& de Reuse, 1996), including epithelial cells that can form polarized monolayers on porous surfaces (Corthésy-Theulaz et al., 1996). To study the pathogenicity of $H$. pylori, with an emphasis on potential VacA effects, we opted for MDCK cells because they form the most tightly sealed polarized monolayers (with the highest TER). When MDCK monolayers were infected with $1.3 \times 10^{8}$ c.f.u. CCUG 17874 (hereafter referred to as CCUG), a strain producing an s1m1 toxin (Telford et al., 1994), bacteria adhered to the monolayer extremely rapidly, reaching within the first hour of infection a plateau of $\sim 1.5 \times 10^{6}$ bound bacteria ( $1 \%$ of the initial inoculum) that remained constant over the time of the experiment (Fig. 1). A comparable efficiency of binding was observed

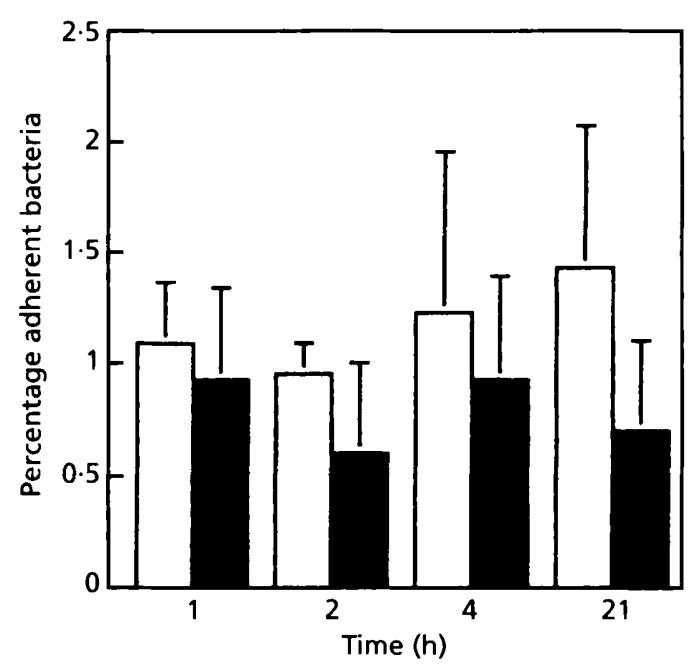

Fig. 1. Adherence of $H$. pylori CCUG and its isogenic vacA mutant to MDCK monolayers at various times after infection. The number of adherent bacteria is expressed as a percentage of the initial bacterial inoculum. Note that $1 \%$ represents $\sim 1.5 \times 10^{6}$ bacteria. White bars show CCUG cells, black bars, CCUG $\operatorname{vac} A$. 
with a vac $A$ isogenic mutant of CCUG. To estimate the m.o.i., defined as the number of bound bacteria per cell in the monolayer, cells forming a monolayer typically used for infection (10-14 days of growth) were recovered by trypsin treatment and counted. Three million cells per well were present, indicating that a fivefold multiplication took place after seeding. From the number of bound bacteria, $1.5 \times 10^{6}$, the m.o.i. can be estimated at 0.5 bound bacteria per MDCK cell. These data indicate that monolayers of MDCK cells are a suitable model for studying $H$. pylori pathogenicity in vitro.

\section{Low doses of adherent $H$. pylori strongly decrease the TER of the monolayers}

To assess whether the infection by $H$. pylori had an effect on the integrity of the monolayers, we followed the variation of the TER, which inversely correlates with the paracellular permeability. Under the above infection conditions, with an inoculum of $1 \cdot 3 \times 10^{8}$ c.f.u. CCUG, we observed a rapid and very marked decrease of the TER (Fig. 2a). After $4 \mathrm{~h}$ infection, the effect on the TER was already pronounced, with a decrease of $60 \%$ of the initial TER values. After $21 \mathrm{~h}$ infection, the effect was maximal with an $85 \%$ decrease. This effect is almost exclusively due to adherent bacteria, because washing a way the unbound bacteria does not change the final TER decrease (data not shown). When the experiment was performed with smaller bacterial loads, an effect on the TER was still observed with similar kinetics but was less pronounced (Fig. 2a). The dose-response curves indicate that an effect can be seen with an m.o.i. as low as $0 \cdot 05$.

\section{TER decrease is due to the production of VacA}

Because it was recently demonstrated that $\mathrm{VacA}$ purified from CCUG decreases the TER of polarized monolayers (Papini et al., 1998), we performed a mutational analysis to confirm that the effect we observed with entire bacteria indeed resulted from the action of the toxin. We constructed an isogenic vacA mutant of CCUG by allelic exchange, where the vacA gene was disrupted by the insertion of a kanamycin-resistance cassette. The mutant does not produce VacA, as assessed by Western blotting, and is consequently inactive in the NRU assay on MDCK cells. When MDCK monolayers were infected with the vacA mutant under standard conditions (m.o.i. 0.5), no significant decrease of the TER was observed: the initial $10 \%$ decrease was only due to the change of the medium (Fig. 2b). No TER decrease was observed even with five times more concentrated inocula (data not shown). These results clearly indicate that the decrease in the TER of MDCK monolayers observed in response to the infection by CCUG depends only on the production of VacA toxin. The effect we observed was not specific to the toxin of CCUG: infections with $H$. pylori SPM 326, another strain producing an $\mathrm{s} 1 \mathrm{~m} 1$ toxin, also led to a decrease in TER. After $21 \mathrm{~h}$ infection, SPM 326 induced a $65 \%$ decrease

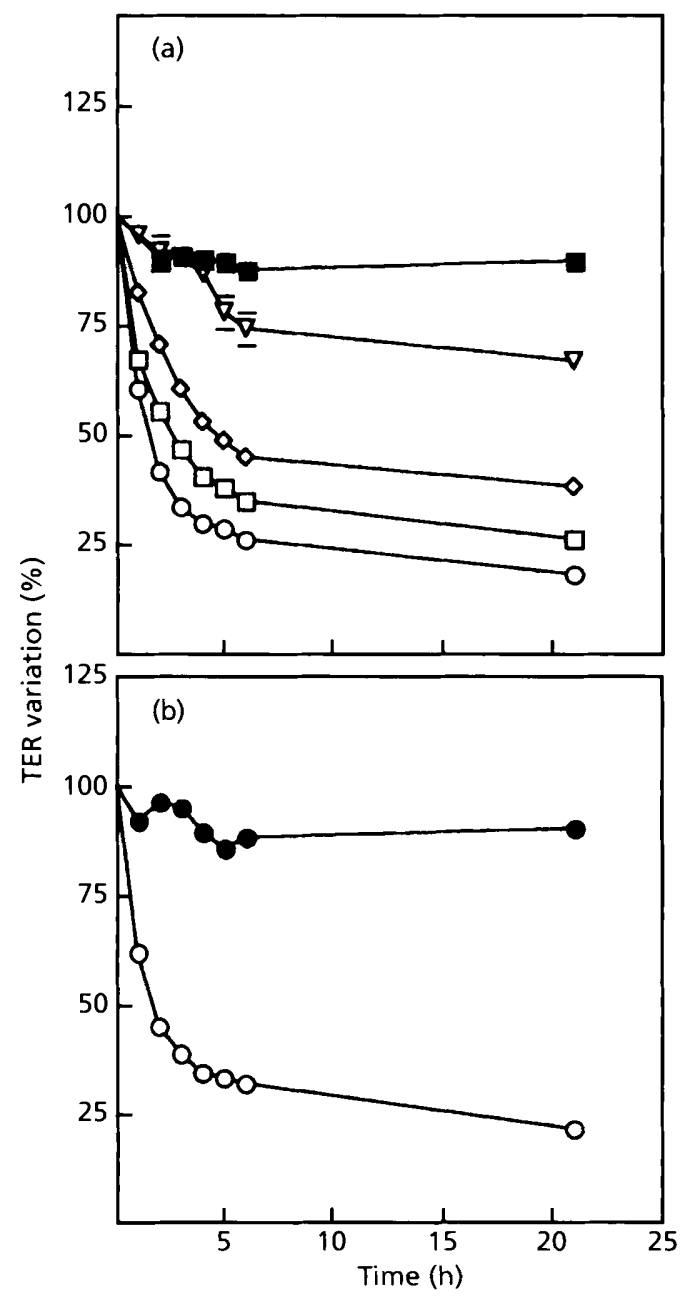

Fig. 2. Effect of (a) various doses of $H$. pylori CCUG and (b) its vacA isogenic mutant on the TER of MDCK monolayers. TER values are expressed as a percentage of the initial TER, prior to infection. The media-alone control $(\boldsymbol{D})$ shows that the TER of uninfected monolayers is stable during the time of the experiment. Symbols: (a) $\nabla, 1.3 \times 10^{7}$ c.f.u.; $\diamond, 4.3 \times 10^{7}$ c.f.u.; $\square, 6.5 \times 10^{7}$ c.f.u.; $0,1.3 \times 10^{8}$ c.f.u.; (b) $\bigcirc$, cCUG; O, CCUG $\operatorname{vac} A$.

of the initial TER values, compared with the $85 \%$ decrease for CCUG (Fig. 3). As above, no effect was seen when an isogenic vacA mutant of SPM 326 was used to infect the monolayers. From these data, it can be concluded that all $\mathrm{m} 1 \mathrm{VacA}$-producing strains induce a decrease of the TER of MDCK monolayers.

\section{m2 toxins decrease the TER of the monolayers}

Some $H$. pylori strains produce toxins presenting a particular mid-region termed $\mathrm{m} 2$, which are inactive in the classical vacuolation assay on HeLa cells (Atherton et al., 1995). Nevertheless, their vacA gene is conserved, suggesting that the physiological properties of $\mathrm{VacA}$ may be different from the well-known vacuolation effect. H. pylori 95-54, a strain presenting an $\mathrm{s} 1 \mathrm{~m} 2$ vacA 


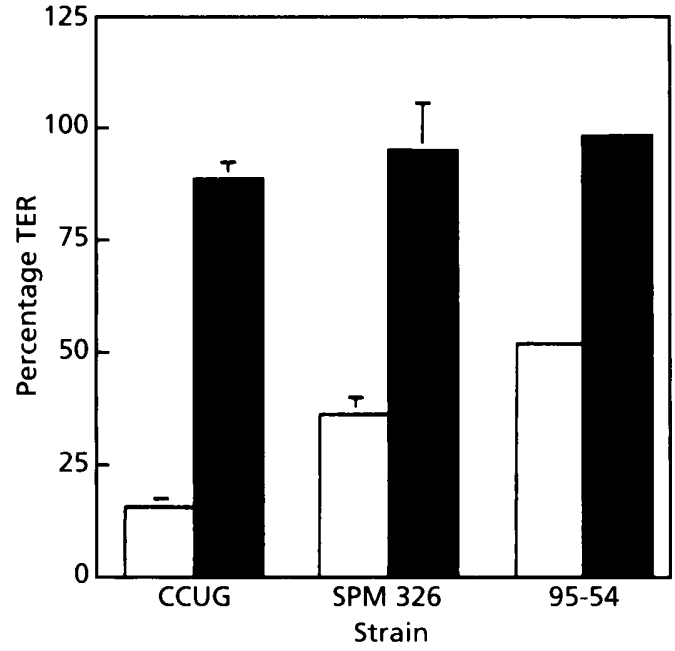

Fig. 3. TER of MDCK monolayers $21 \mathrm{~h}$ after infection with $H$. pylori strains. White bars indicate wild-type, black bars show the vacA mutants.

(a)
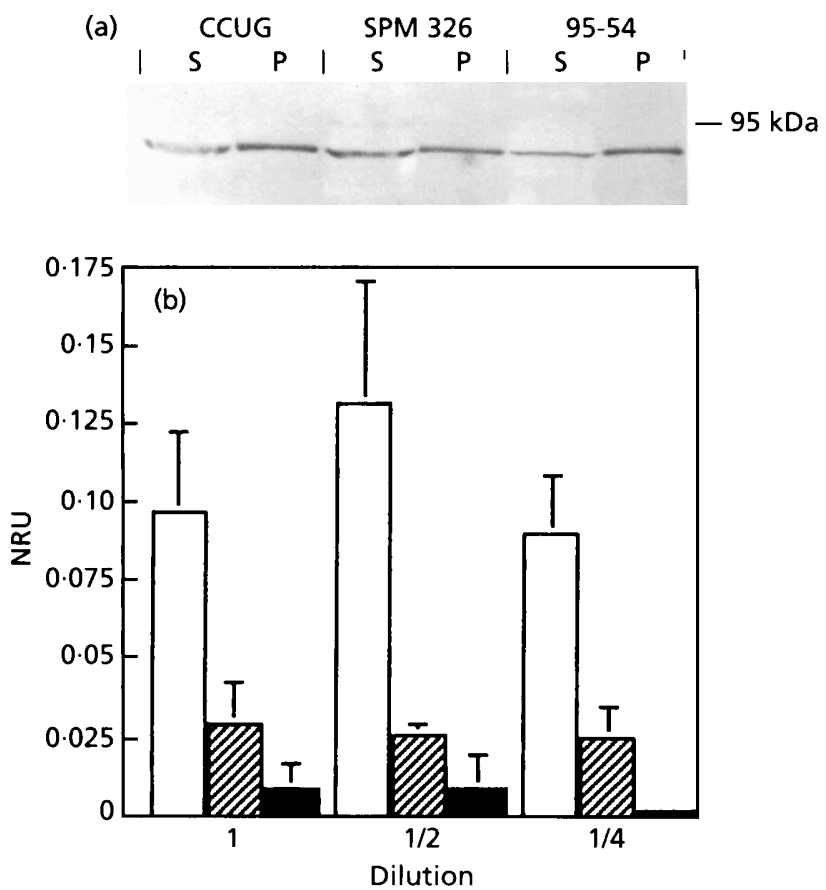

Fig. 4. (a) Western-blot detection of VacA produced and released by $H$. pylori strains CCUG, SPM 326 and 95-54. P, pellet; S, supernatant. (b) NRU spectrophotometric quantification of vacuolation induced in MDCK cells by succesive dilutions of the water extracts of the various $H$. pylori strains used in this study. NRU values are the difference of absorbance at $534 \mathrm{~nm}$ and $405 \mathrm{~nm}$ after subtraction of the background optical density of CCUG vacA. White bars show values for CCUG, hatched bars, SPM 326 and black bars, 95-54.

genotype, was isolated from a patient with peptic ulcer. It produces a toxin (Fig. 4a) that, in contrast to CCUG and SPM 326, does not induce vacuoles in sparse MDCK

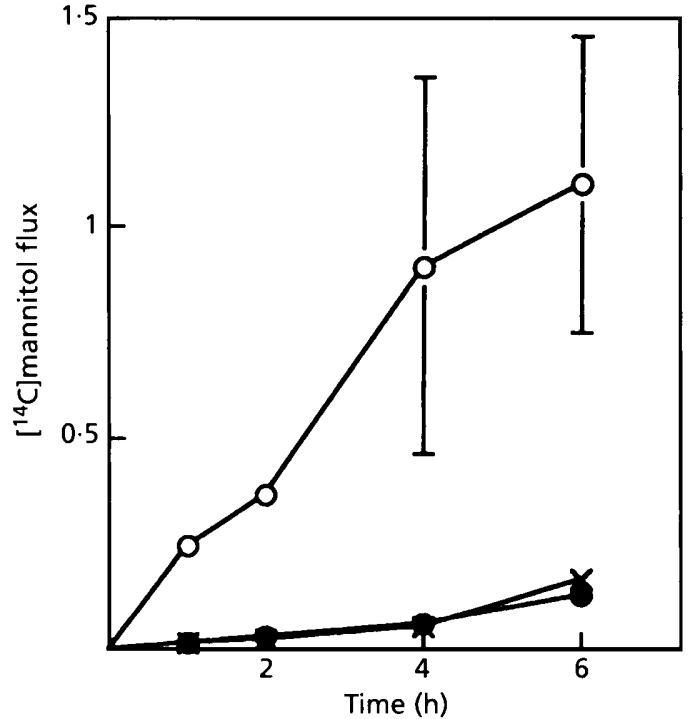

Fig. 5. Kinetics of $\left[{ }^{14} \mathrm{C}\right]$ mannitol penetration through MDCK monolayers $21 \mathrm{~h}$ after infection with CCUG and its isogenic vacA mutant. Values are defined as the percentage of radioactivity in the apical compartment relative to the total radioactivity added to the basolateral compartment. $x$, control; O, CCUG;, , CCUG vacA.

cells (Fig. 4b). This VacA isoform was, however, perfectly active since infection of the MDCK monolayers with 95-54 induced a notable decrease of the TER : after $21 \mathrm{~h}$ infection, the TER was only $50 \%$ of the initial values (Fig. 3). As before, no effect on the TER was obtained with a $95-54 \mathrm{vac} A$ isogenic mutant constructed by allelic exchange. It can be concluded from these data that the decrease in TER of MDCK monolayers is a more reliable assay for VacA toxicity than the vacuolation activity and that the $\mathrm{m} 2$ toxins are perfectly active.

\section{TER decrease, concomitant with an increased paracellular permeability, is due to the toxin associated with the bacteria}

To test whether the decrease in TER led to an increase of paracellular permeability, as reported for the purified toxin (Papini et al., 1998), we measured the flux of $\left[{ }^{14} \mathrm{C}\right]$ mannitol, a marker molecule that uses mostly a paracellular route to permeate through a polarized epithelium. MDCK monolayers infected with CCUG for $21 \mathrm{~h}$ and showing an $85 \%$ decrease of TER presented a fivefold increase of mannitol flux over $6 \mathrm{~h}$ when compared to monolayers that were uninfected or infected with an isogenic vacA mutant (Fig. 5).

Acidic $\mathrm{pH}$ strongly potentiates the vacuolating activity (de Bernard et al., 1995) and the TER-decreasing activity (Papini et al., 1998) of the purified toxin, and hence this was tested with whole bacteria. When MDCK monolayers were infected with CCUG preincubated at $\mathrm{pH} 5 \cdot 4$, essentially the same effect on the TER as in the experiments performed at $\mathrm{pH} 7 \cdot 4$ was detected. Thus, 


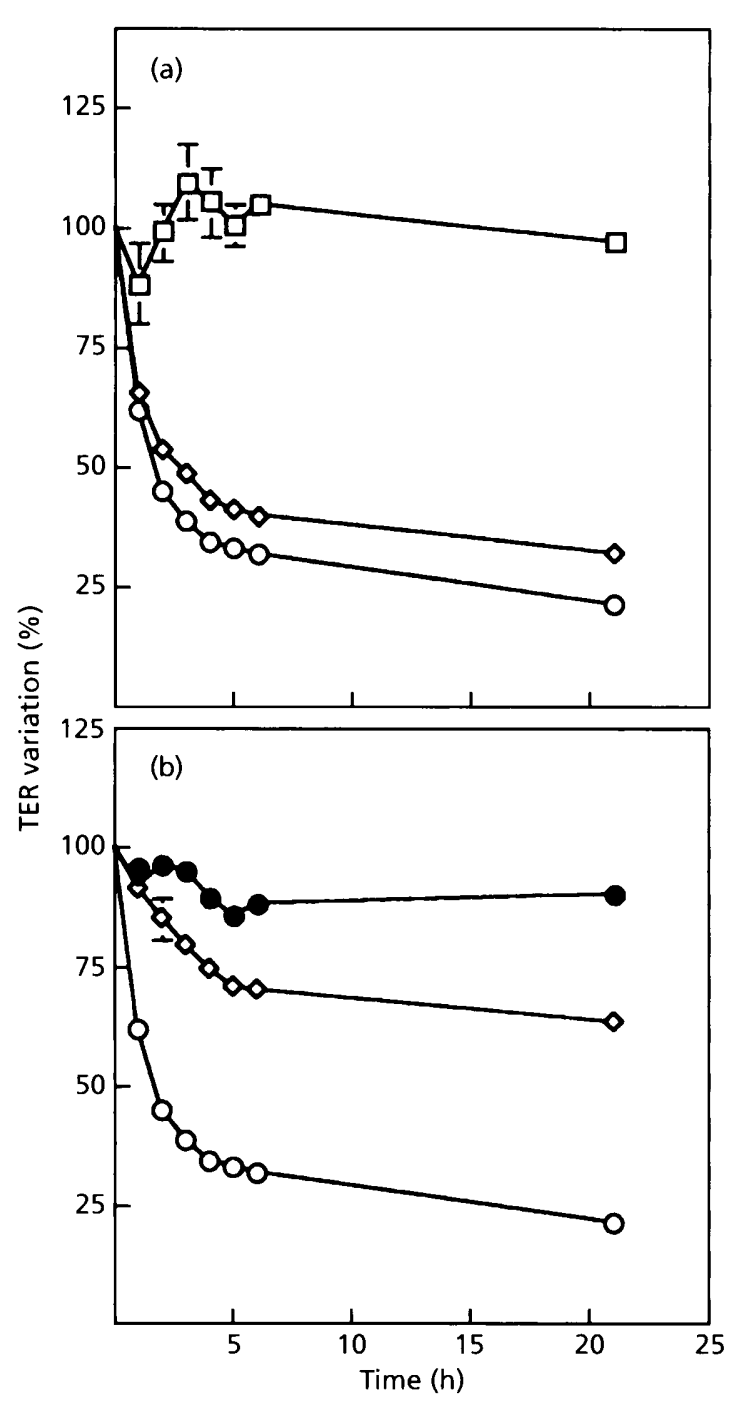

Fig. 6. Comparison of the TER effects induced by (a) the secreted and bacteria-bound VacA toxin and (b) an isogenic CCUG vacA mutant 'functionally complemented' with acidactivated purified toxin. TER values are expressed as the percentage of the initial TER. Symbols: (a) $\square$, CCUG supernatant; $\diamond$, CCUG pellet; $\bigcirc$, CCUG; (b) $\bullet$, CCUG vacA; $\diamond$, CCUG vacA + VacA; O, CCUG.

under the present experimental conditions, the toxin did not require the low-pH activation which is known to be associated with a dissociation of the secreted oligomeric toxin into monomers (Cover et al., 1997). This suggested the possibility that the TER decrease we observed was due to the toxin that remained associated with the bacteria, that may be present in its active monomeric form. Bacteria were centrifuged prior to infection to remove any toxin released in the medium, and the bacterial pellet was used to infect the monolayers. The decrease in TER was only slightly smaller that that observed with non-centrifuged bacterial cultures (Fig. 6a). Accordingly, no decrease in TER was observed when the supernatant, containing roughly half of the toxin produced by the bacteria, was added to the monolayers (Fig. 6a). Moreover, the effect was not due to toxin released by the bacterium upon contact with the cells, as the medium from the upper compartment taken at 1 and $5 \mathrm{~h}$ after infection was unable to induce any decrease in TER when added to new monolayers (data not shown). Moreover, when an isogenic vacA mutant was incubated with purified toxin prior to infecting the monolayers (a process that can be viewed as functional complementation), the TER-decreasing activity was partly restored (Fig. 6b). Interestingly, this was only observed when the toxin was preincubated at acid $\mathrm{pH}$, a treatment known to induce the dissociation of the oligomeric VacA into monomers (Cover et al., 1997). Taken together, these data suggest that the effect of VacA on the TER, corresponding to an increase of paracellular permeability, is due exclusively to constitutively active toxin molecules that remain associated with the bacteria.

\section{DISCUSSION}

In vitro models of infection are likely to help in solving crucial but still obscure aspects of infections with various bacteria, including $H$. pylori. Cellular models based on monolayers of polarized epithelial cells, which mimic the situation encountered by $H$. pylori in vivo, provide an additional insight over the non-polarized cells in culture that are most frequently used. Recently, Corthésy-Theulaz et al. (1996) used T84 cells and suggested that MDCK cells could also be used. Indeed, we have shown that $H$. pylori adheres very rapidly to MDCK monolayers, reaching a saturation level within $1 \mathrm{~h}$ of infection. This is comparable to what was reported for T84 monolayers and it confirms that appropriate receptors for $H$. pylori (Labigne \& de Reuse, 1996) are present on the surface of these cells. In addition, the cell biology of MDCK is better studied than that of T84 cells, and MDCK cells form more tightly sealed monolayers that permit the testing of bacterial effects on the permeability properties of the monolayer.

By using monolayers of epithelial cells, including MDCK cells, purified VacA was recently found to selectively increase paracellular permeability to ions and lowmolecular-mass molecules, presumably by loosening tight junctions between cells (Papini et al., 1998). Here we extend these findings under more physiological conditions, using viable bacteria. We show that extremely small numbers of bacteria (m.o.i. as low as 0.5 ) are sufficient to obtain a decrease in TER similar to that seen with very large amounts of purified toxin (Papini et al., 1998), suggesting that the process is much more efficient with viable bacteria. One possible explanation is that an intimate contact between the bacteria and the cells may favour the delivery of the toxin to the cells. A mutational analysis clearly demonstrates that $\mathrm{VacA}$ is necessary and sufficient to induce an increase in the permeability of the monolayer. Indeed, isogenic vac $A$ mutants did not induce any noticeable decrease of the TER, unless they had been complemented with purified 
toxin. Moreover, this study presents two novel findings that may be physiologically relevant to $H$. pylori pathogenicity. Firstly, a TER decrease was observed with all VacA-producing strains tested, independently of their vacuolating activity. For example, 95-54, which produces an $\mathrm{s} 1 \mathrm{~m} 2$ toxin that induces no vacuoles in MDCK sparse cells (Fig. 4b), was able to induce a TER decrease on MDCK monolayers. Thus, in contrast to the vacuolation activity, which is dependent on the cell line used (Pagliaccia et al., 1998), the decrease in TER in MDCK monolayers may be a more reliable assay for VacA toxicity. This effect may be particularly relevant to the role of VacA in vivo and would also account for the fact that vacA $\mathrm{m} 2$ alleles have been conserved throughout the evolution. Secondly, the decrease in TER, presumably caused by toxin that remains associated with the bacterial surface, is not, in contrast to other described activities of VacA (de Bernard et al., 1995; Papini et al., 1998), potentiated by acid pretreatment. Since acid treatment results in the dissociation of the oligomeric VacA into monomers (Cover et al., 1997; Molinari et al., 1998b), suggesting that the monomers are the active form of the toxin, it is tempting to speculate that the toxin present on the bacterial surface is already in its active, possibly monomeric, form. This idea is strengthened by the fact that acid-activated toxin was the only form able to functionally complement a vacA mutant in the TER decrease assay (Fig. 6a). However, using monolayers of MDCK cells (or T84), Corthésy-Theulaz et al. (1996) did not observe any TER decrease after bacterial infection. This absence of effect may be due to a lack of toxin production, since the bacterial strains they used were not genetically characterized, or to the fact that TER values of the monolayers they used were more than 5 times lower than those routinely reached in the present study. This last discrepancy was possibly due to differences in culture methods or to the use of slightly different cell lines. Another report showed that sonicates of $H$. pylori were able to induce a TER decrease in T84 monolayers (Terrés et al., 1998), but this effect was different from the present one because it was rapidly reversible and non-dependent on $v a c A$ expression.

Taken together, previous (Papini et al., 1998) and present results allow one to envisage a likely scenario directly linking a defined VacA effect in vitro to toxininduced tissue damage seen in vivo. Briefly, intimate contact between $H$. pylori and the polarized monolayers of gastric epithelial cells could favour the delivery of a monomeric form of the toxin, associated with the bacterial surface, into the epithelial cell cytosol. As a consequence of a still-uncharacterized intracellular action, the toxin would lead to an increase of the paracellular permeability, rendering the gastric barrier more fragile and susceptible to later attack. It should be emphasized that unlike other bacterial toxins, such as fragilysin from Bacteroides fragilis (Obiso et al., 1997), VacA does not completely disrupt the tight junctions between cells, as the TER values after infection are indicative of a sealed monolayer. Therefore, the loosening of the intercellular junctions induced by VacA is probably only an initial step in the ulcerogenesis. As described for other pathogens (McCormick et al., 1997, 1998), a subsequent trans-epithelial migration of polymorphonuclear leukocytes could accelerate the disorganization of the gastric epithelium and ultimately lead to its disruption, as observed in patients with peptic ulcers.

\section{ACKNOWLEDGEMENTS}

J.-M. Reyrat and L. Sartori contributed equally to this work. We are grateful to T. Msadek, G. Vitale and P. Washbourne for critical reading of the manuscript. We thank our colleagues for fruitful discussions. This work was supported by EC grants (Biomed BMH4 CT97 2410 and TMR FMRX CT96 0004), by MURST $60 \%$ and $40 \%$, by C.N.R. Target Project on Biotechnology (97 01168 PF49) and by the ArmeniseHarvard Medical School Foundation.

\section{REFERENCES}

Akopyants, N. S., Clifton, S. W., Kersulyte, D. \& 7 other authors (1998)CR Analyses of the cag pathogenicity island of Helicobacter pylori. Mol Microbiol 28, 37-53.

Atherton, J. C., Cao, P., Peek, R. M., Jr, Tummuru, M. K. R., Blaser, M. J. \& Cover, T. L. (1995). Mosaicism in vacuolating cytotoxin alleles of Helicobacter pylori. J Biol Chem 270, 17771-17777.

de Bernard, M., Papini, E., de Filippis, V., Gottardi, E., Telford, J., Manetti, R., Fontana, A., Rappuoli, R. \& Montecucco, C. (1995). Low $\mathrm{pH}$ activates the vacuolating toxin of Helicobacter pylori, which becomes acid and pepsin resistant. J Biol Chem 270, 23937-23940.

de Bernard, M., Arico, B., Papini, E., Rizzuto, R., Rappuoli, R. \& Montecucco, C. (1997). Helicobacter pylori toxin VacA induces vacuole formation by acting in the cell cytosol. Mol Microbiol 26, $665-674$.

Blaser, M. J. (1993). Helicobacter pylori: microbiology of a 'slow' bacterial infection. Trends Microbiol 1, 255-260.

Censini, S., Lange, C., Xiang, Z., Crabtree, J. E., Ghiara, P., Borodovsky, M., Rappuoli, R. \& Covacci, A. (1996). cag, a pathogenicity island of Helicobacter pylori, encodes type Ispecific and disease-associated virulence factors. Proc Natl Acad Sci USA 93, 14648-14653.

Corthésy-Theulaz, I., Porta, N., Pringault, E., Racine, L., Bogdanova, A., Kraehenbuhl, J.-P., Blum, A. L. \& Michetti, P. (1996). Adhesion of Helicobacter pylori to polarized T84 human intestinal cell monolayers is pH dependent. Infect Immun 64, $3827-3832$.

Cover, T. L., Hanson, P. I. \& Heuser, J. E. (1997). Acid-induced dissociation of VacA, the Helicobacter pylori vacuolating cytotoxin, reveals its pattern of assembly. J Cell Biol 138, 759-769.

Figura, N., Guglielmetti, P., Rossolini, A., Barberi, A., Cusi, G., Musmanno, R., Russi, M. \& Quaranta, S. (1989). Cytotoxin production by Campylobacter pylori strains isolated from patients with peptic ulcers and from patients with chronic gastritis only. J Clin Microbiol 27, 22.5-226.

Garner, J. A. \& Cover, T. L. (1996). Binding and internalization of Helicobacter pylori vacuolating cytotoxin by epithelial cells. Infect Immun 64, 4197-4203.

Labigne, A. \& de Reuse, H. (1996). Determinants of Helicobacter pylori pathogenicity. Infect Agents Dis 5, 191-202. 
Leunk, R. D., Johnson, P. T., David, B. C., Kraft, W. G. \& Morgan, D. R. (1988). Cytotoxic activity in broth-culture filtrates of Campylobacter pylori. J Med Microbiol 26, 93-99.

Lupetti, P., Heuser, J. E., Manetti, R., Massari, P., Lanzavecchia, S., Bellon, P. L., Dallai, R., Rappuoli, R. \& Telford, J. L. (1996). Oligomeric and subunit structure of the Helicobacter pvlori vacuolating cytotoxin. J Cell Biol 133, 801-807.

McCormick, B. A., Nusrat, A., Parkos, C. A., D'Andrea, L., Hofman, P. M., Carnes, D., Liang, T. W. \& Madara, J. L. (1997). Unmasking of intestinal epithelial lateral membrane $\beta$ - 1 integrin consequent to transepithelial neutrophil migration in vitro facilitates inumediated invasion by Yersinia pseudotuberculosis. Infect Immun 65, 1414-1421.

McCormick, B. A., Siber, A. M. \& Maurelli, A. T. (1998). Requirements of the Shigella flexneri virulence plasmid in the ability to induce trafficking of the neutrophils across polarized monolayers of the intestinal epithelium. Infect Immun 66, 4237-4243.

Manetti, R., Massari, P., Burroni, D. \& 7 other authors (1995). Helicobacter pylori cytotoxin: importance of native conformation for induction of neutralizing antibodies. Infect Immun 63, 4476-4480.

Marchetti, M., Aricò, B., Burroni, D., Figura, N., Rappuoli, R. \& Ghiara, P. (1995). Development of a mouse model of Helicobacter pylori infection that mimics human disease. Science 267, $1655-1658$

Marchini, A., Massari, P., Manetti, R. \& Olivieri, R. (1994). Optimized conditions for the fermentation of Helicobacter pvlori and production of vacuolating cytotoxin. FEMS Microbiol Lett $124,55-60$.

Massari, P., Manetti, R., Burroni, D., Nuti, S., Norais, N., Rappuoli, R. \& Telford, J. L. (1998). Binding of the Helicobacter pylori vacuolating cytotoxin to target cells. Infect Immun 66, 398 1-3984.

Molinari, M., Galli, C., Norais, N., Telford, J. L., Rappuoli, R., Luzio, J. P. \& Montecucco, C. (1997). Vacuoles induced by Helicobacter pylori toxin contain both late endosomal and lysosomal markers. J Biol Chem 272, 25339-25344.

Molinari, M., Salio, M., Galli, C., Norais, N., Rappuoli, R., Lanzavecchia, A. \& Montecucco, C. (1998a). Selective inhibition of li-dependent antigen presentation by Helicobacter pylori toxin VacA. I Exp Med 187, 135-140.

Molinari, M., Galli, C., de Bernard, M., Norais, N., Ruysschaert, J. M., Rappuoli, R. \& Montecucco, C. (1998b). The acid activation of Helicobacter pylori toxin VacA: structural and membranebinding studies. Biochem Biophys Res Commun 248, 334-340.

Montecucco, C., Papini, E. \& Schiavo, G. (1994). Bacterial protein toxins penetrate cells via a four-step mechanism. FEBS Lett $\mathbf{3 4 6}$, 92-98.

Obiso, R. J., Jr, Azghani, A. O. \& Wilkins, T. D. (1997). The Bacteroides fragilis toxin fragilysin disrupts the paracellular barrier of epithelial cells. Infect Immun 65, 1431-1439.

Pagliaccia, C., de Bernard, M., Lupetti, P. \& 7 other authors (1998). The $\mathrm{m} 2$ form of the Helicobacter pylori cytotoxin has cell type- specific vacuolating activity. Proc Natl Acad Sci USA 95, 10212-10217.

Papini, E., Bugnoli, M., de Bernard, M., Figura, N., Rappuoli, R. \& Montecucco, C. (1993). Bafilomycin Al inhibits Helicobacter pylori-induced vacuolization of HeLa cells. Mol Microbiol 7, 323-327.

Papini, E., de Bernard, M., Milia, E., Bugnoli, M., Zerial, M., Rappuoli, R. \& Montecucco, C. (1994). Cellular vacuoles induced by Helicobacter pylori originate from late endosomal compartments. Proc Natl Acad Sci USA 91, 9720-9724.

Papini, E., Satin, B., Bucci, C., de Bernard, M., Telford, J. L., Manetti, R., Rappuoli, R., Zerial, M. \& Montecucco, C. (1997). The small GTP-binding protein rab7 is essential for cellular vacuolation induced by Helicolacter pylori cytotoxin. EMBO J 16, 15-24.

Papini, E., Satin, B., Norais, N., de Bernard, M., Telford, J. L., Rappuoli, R. \& Montecucco, C. (1998). Helicobacter pylori vacuolating toxin increases the permeability of polarized epithelial cell monolayers. J Clin Inu'est 102, 813-820.

Parsonnet, J., Friedman, G. D., Vandersteen, D. P., Chang, Y., Vogelman, J. H., Orentreich, N. \& Sibley, R. K. (1991). Helicobacter pvlori infection and the risk of gastric carcinoma. New Engl J Med 325, 1127-1131.

Radin, M. J., Eaton, K. A., Krakowka, S., Morgan, D. R., Lee, A., Otto, G. \& Fox, J. (1990). Helicobacter pylori gastric infection in gnotobiotic beagle dogs. Infect Immun 58, 2606-2612.

Satin, B., Norais, N., Telford, J., Rappuoli, R., Murgia, M., Montecucco, C. \& Papini, E. (1997). Effect of Helicobacter pylori vacuolating toxin on maturation and extracellular release of procathepsin D and on epidermal growth factor degradation. $J$ Biol Chem 272, 25022-25028.

Segal, E. D., Lange, C., Covacci, A., Tompkins, L. S. \& Falkow, S. (1997). Induction of host signal transduction pathways by Helicobacter pylori. Proc Natl Acad Sci USA 94, 7595-7599.

Telford, J., Ghiara, P., Dell'Orco, M. \& 11 other authors (1994). Gene structure of the Helicobacter pylori cytotoxin and evidence of its key role in gastric disease. J Exp Med 179, 1653-1658.

Terrés, A. M., Pajares, J. M., Hopkins, A. M., Murphy, A., Moran, A., Baird, A. W. \& Kelleher, D. (1998). Helicobacter pylori disrupts epithelial barrier function in a process inhibited by protein kinase C activators. Infect Immun 66, 2943-2950.

Trieu-Cuot, P., Gerbaud, G., Lambert, T. \& Courvalin, P. (1985). In vivo transfer of genetic information between Gram-positive and Gram-negative hacteria. EMBO J 4, 3583-3587.

Xiang, Z., Censini, S., Bayeli, P. F., Telford, J. L., Figura, N., Rappuoli, R. \& Covacci, A. (1995). Analysis of expression of CagA and VacA virulence factors in 43 strains of Helicobacter pylori reveals that clinical isolates can be divided into two major types and that CagA is not necessary for expression of the vacuolating cytotoxin. Infect Immun 63, 94-98.

Received 22 January 1999; revised 14 April 1999; accepted 11 May 1999 